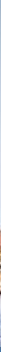

\title{
ANTIBIOTIC RESISTANCE IN ENT - PSEUDOMONAS AERUGINOSA AND OTITIS EXTERNA
}

\section{Bilal Ibrahim¹, A. E. Louise McMurran², Patrick M. Spielmann²}

${ }^{1}$ University of Dundee ${ }^{2}$ NHS Tayside

\section{Background}

Antibiotic resistance is a global concern

Pseudomonas aeruginosa is known to have resistance rates

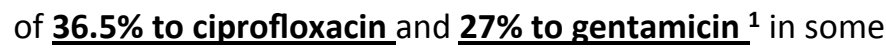
studies

Most cases of pseudomonal otitis externa are managed empirically with topical ciprofloxacin or gentamicin

A large proportion of patients could be receiving ineffective treatment

\section{Objectives}

To evaluate the incidence of resistance in Pseudomonal ear swabs in NHS Tayside

To evaluate any change in resistance over time, from January 2011 to October 2017

\section{Methods}

All Pseudomonas positive ear swabs from January 2011 until October 2017 were analysed, with resistance rates to ciprofloxacin and gentamicin calculated.

\section{Overall Results}

\begin{tabular}{|c|c|c|c|}
\hline OVERALL & Sensitive & Resistant & Intermediate \\
\hline Gentamicin $(\mathrm{n}=3509)$ & $90.7 \%$ & $6.6 \%$ & $2.8 \%$ \\
\hline Ciprofloxacin $(\mathrm{n}=3410)$ & $95.3 \%$ & $2.1 \%$ & $2.6 \%$ \\
\hline & Gentamicin & \multicolumn{2}{c|}{ Ciprofloxacin } \\
\hline
\end{tabular}

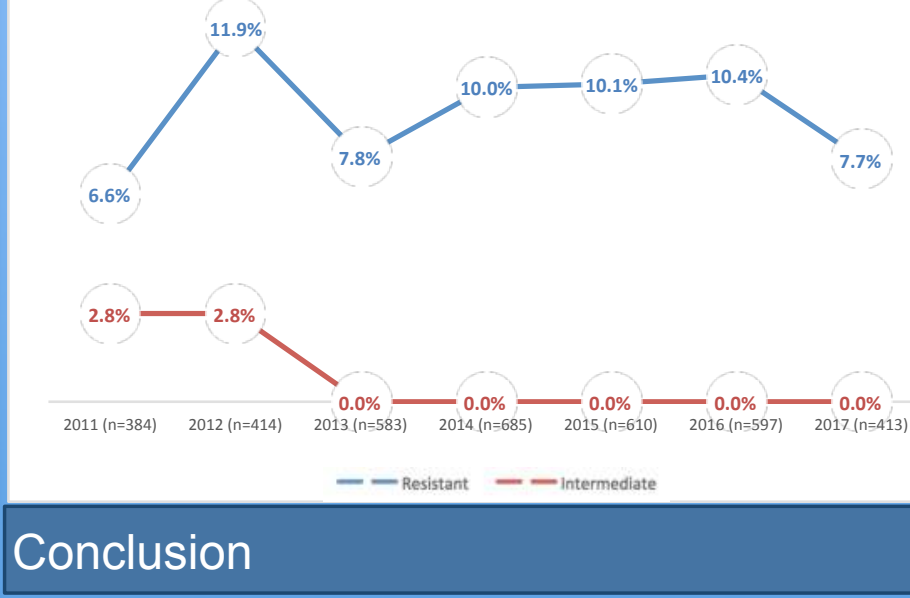

Although worldwide studies have shown significant rates of Pseudomonas resistance this trend is not repeated in our population. Resistance peaked in 2012, and has remained steady since.

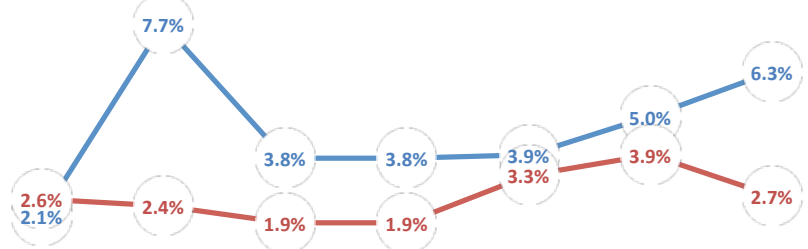

$2011(n=384) \quad 2012(n=414) \quad 2013(n=583) \quad 2014(n=685) \quad 2015(n=610) \quad 2016(n=597) \quad 2017(n=413)$ - Resistant Intermediate

\section{References}

${ }^{1}$ TEIXEIRA B, RODULFO H, CARREÑO N, GUZMÁN M, SALAZAR E, DONATO MD. AMINOGLYCOSIDE RESISTANCE GENES IN Pseudomonas aeruginosa ISOLATES FROM CUMANA, VENEZUELA. Rev Inst Med Trop São Paulo [Internet]. 2016 Mar 22 [cited 2017 Nov 23];58. Available from: https://www.ncbi.nlm.nih.gov/pmc/articles/PMC4804550/ 